ers) has written of the powerful link between storytelling in group situations and subsequent action by individual participants. ${ }^{16}$ Because of the detailed analysis of what actually went on in the groups, this study has contributed considerably to the research literature on group based education in diabetes (summarised on bmj.com).

This study has provided unique insights into the feasibility of setting up diabetes support and education groups for both bilingual health advocates and service users and into the process of learning, empowerment, and change in such groups. The impact of the intervention should now be tested in a randomised controlled trial.

We thank the service users, bilingual health advocates, and many other stakeholders who participated so enthusiastically in setting up and evaluating the groups described here. Their names are listed in the "Sharing stories" workbook. We especially thank John Eversley, Jill Russell, Anita Berlin, and Farida Malik for conceptual and practical input at different stages.

Contributors: See bmj.com

Funding: The study was funded by Diabetes UK.

Competing interests: None declared.

Ethical approval: The local research ethics committee approved the study.

1 Greenhalgh T, Griffiths T, Thomas K, Wheeler J, Raleigh V. Reducing inequalities in diabetes: report of the Expert Reference Group for the National Service Framework for Diabetes. London: Department of Health, 2001
2 Nazroo NY. The health of Britain's ethnic minorities. London: Policy Studies Institute, 1997.

3 Blaxter M. Black and minority ethnic groups in England: health and lifestyles. London: Health Education Authority, 1994

4 Norris SL, Engelgau MM, Narayan KMV. Effectiveness of selfmanagement training in type 2 diabetes. Diabetes Care 2001;24:561-87.

5 Loveman E, Cave C, Green C, Royle P, Dunn N, Waugh N. The clinical and cost-effectiveness of patient education models for diabetes: a systematic revie and economic evalion.

6 Krichbaum K, Aarestad V, Buethe M. Exploring the connection between self-efficacy and effective diabetes self-management. Diabetes Educ 2003;29:653-62

7 Steed L, Cooke D, Newman S. A systematic review of psychosocial outcomes following education, self-management and psychological interventions in diabetes mellitus. Patient Educ Couns 2003;51:5-15.

8 Meyer J. Using qualitative methods in health related action research. $B M J$ Meyer J. Using qua

9 Waterman H, Tillen D, Dickson R, de Koning K. Action research: a systematic review and guidance for assessment. Health Technol Assess 2001;5(23):iii, 1-157.

10 Greenhalgh T, Collard A, Begum N. 'Sharing stories': an action research project to develop group education in diabetes for health advocates and 'hard to reach' service users. Pract Diabetes Int 2005; in press.

11 Kolb DA. The process of experiential learning. In: Thorpe M, Edwards R, Hanson A, eds. Culture and processes of adult learning. London: Routledge, 1993:138-56.

12 Elwyn G, Greenhalgh T, Macfarlane F. Groups-a hands-on guide to small group work in education, management and research. Oxford: Radcliffe, 2000.

13 Greenhalgh T. Storytelling should be targeted where it is known to have greatest added value. Med Educ 2001;35:818-9.

14 Campbell M, Fitzpatrick R, Haines A, Kinmonth AL, Sandercock P, Spiegelhalter D, et al. Framework for design and evaluation of complex interventions to improve health. BMJ 2000;321:694-6.

15 Hawe P, Shiell A, Riley T. Complex interventions: how "out of control" can a randomised controlled trial be? BMJ 2004;328:1561-3.

16 Denning S. The springboard: how storytelling ignites action in knowledge-era organisations. New York: Butterworth-Heinemann, 2000.

\title{
Commentary: Using patients' narratives in complex research
}

\author{
Ross E G Upshur
}

The use of narratives is attracting attention in health care as a means of exploring and sharing experiences of health, interactions with the health care system, and as a research method, in and of itself. How narratives function as part of a complex research programme is a less explored terrain. Greenhalgh and colleagues are to be commended for their innovative and novel approach to creating an intervention for diabetes education with the specific aim of engaging bilingual health advocates to facilitate narrative or story telling approaches as a part of a programme to improve diabetes management for a vulnerable and neglected population. ${ }^{1}$

The study is itself part of a story. Like an early chapter in a book, what we see before us is only an indication of what is to come, and as with all good stories it clarifies some dimensions of the plot but leaves others untold. Greenhalgh and colleagues clearly show the difficulties and describe the barriers required to get an action oriented research programme functioning, and they are candid in both their successes and failures. It seems that a user group led by a bilingual health advocate can be successfully implemented in some circumstances, but not in all. Considerable effort is required to ensure the acceptability and sustainability of the programme.

I wonder whether the authors have explored the possible harms associated with this type of research. One of the important findings was that participants did not compare their blood glucose results to previous results, but compared their results to each other's: "She didn't have a second helping and, look, her result is better than yours." Considerable trust and support is required for this kind of disclosure and public discussion of a personal narrative in a public or group setting. I hope that victim blaming didn't have an important role and that surveillance, patrolling, and intrusiveness did not become a part of the lives of the people who shared information about their diabetes. An example would be a social occasion when people say "You can't eat that, you're diabetic." The ethical demands of action research are relevant but are rarely discussed.

The story of this study is not yet completed. This report will leave readers anxious for the next installment. Greenhalgh and colleagues have established the feasibility of establishing diabetes support and education groups with bilingual health advocates and service users, revealing novel insights. They now propose a randomised control trial. Will they engage their study communities in the creation of this randomised trial, particularly seeking input from the group on the desired outcome measures and the magnitude of effect expected by such an intervention? The importance placed on outcomes by different participants in the research process varies greatly. Narrative approaches are ideally suited to capturing this diversity and I hope that, true to the researchers' methods, the community has as much input in the conception of the randomised trial as it has had into the development of this important study.

Competing interests: None declared.

1 Greenhalgh T, Collard A, Begum N. Sharing studies of complex intervention for diabetes education in minority ethnic groups who do not speak English. BMJ 2005;330:628-31.

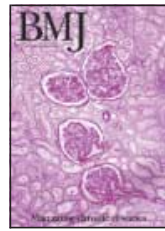

Department of Family and Community Medicine,

University of Toronto, Toronto, ON, Canada M5T 1W7

Ross E G Upshur associate professor

Ross.Upshur@sw.ca 